\title{
Práticas de Psicólogos na Estratégia Saúde da Família: Poder Simbólico e Autonomia Profissional
}

\author{
Léo Barbosa Nepomuceno ${ }^{1}$ \\ ${ }^{1}$ Universidade Federal do Ceará, CE, Brasil. \\ Maria Lúcia Magalhães Bosi ${ }^{1}$ \\ ${ }^{1}$ Universidade Federal do Ceará, CE, Brasil.
}

\author{
Magda Dimenstein ${ }^{2}$ \\ ${ }^{2}$ Universidade Federal do Rio Grande do Norte, RN, Brasil. \\ Ricardo José Soares Pontes ${ }^{1}$ \\ ${ }^{1}$ Universidade Federal do Ceará, CE, Brasil.
}

Resumo: Este estudo, orientado pelo enfoque qualitativo de pesquisa social em saúde, discute a inserção de psicólogos nos serviços de atenção primária do Sistema Único de Saúde, por meio da Estratégia Saúde da Família (ESF). O objetivo do trabalho é analisar especificidades da atuação dos psicólogos nos referidos serviços, focalizando nas práticas desenvolvidas visando ao reconhecimento e à autonomia profissional. A técnica empregada para a construção do material empírico foi a entrevista semiestruturada, junto a 18 psicólogos com ampla experiência na atenção e formação para a ESF. O referencial teórico adotado se orienta pelos conceitos de poder simbólico e habitus, centrais na sociologia de Pierre Bourdieu. Também são retomados elementos teóricos procedentes da sociologia das profissões. Como resultados, evidenciam-se tensões concernentes às lutas por autonomia profissional. Um habitus profissional se apresenta como ilustrativo das práticas ditas específicas e distintivas do psicólogo: o saber lidar com conflitos interpessoais; ser agente problematizador e mediador nas relações interprofissionais; e a capacidade de reconhecer processos históricos constituintes das subjetividades e tramas relacionais. Alguns desafios à autonomia profissional são identificados: a expectativa social e o prestígio associados aos modelos clássicos de atuação clínica; o acolhimento de uma sobrecarga de trabalho em territórios de grande extensão; e a necessidade de elaborar posicionamentos que façam contraponto e complemento ao modelo biomédico.

Palavras-chave: Psicologia, Sistemas de Saúde, Atenção Primária à Saúde, Profissionalização, Atenção Básica à Saúde.

\section{Practices of Psychologists in the Family Health Strategy: Symbolic Power and Professional Autonomy}

\begin{abstract}
This study, oriented by the health qualitative research approach, addresses the inclusion of psychologists in primary care services of the Brazilian Unified Health System by the Family Health Strategy (FHS). The objective is to analyze the specificity of the psychologists' performance in these health services, focusing on struggles for recognition and professional autonomy. Concerning to the construction of the empirical material, the technique employed was the semi-structured, based on dialogue with 18 psychologists with extensive professional experience in basic Health care and training for the FHS. The theoretical framework adopted is based on the concepts of symbolic power and habitus, central concepts in the sociology of Pierre Bourdieu. Also theoretical elements from the sociology of professions are used in the analysis. The study results show relevant tensions and struggles involving professional autonomy. A professional habitus is a illustrative of the specific and distinctive practices of the psychologist: knowing how to deal with interpersonal conflicts; being a problematizing agent and mediator in
\end{abstract}


interprofessional relationships; the capacity to be able to recognize historical processes being a problematizing agent and mediator in interprofessional relationships; the capacity to be able to recognize historical processes involved in the subjective production of the group and their relationships. Some challenges to professional autonomy are identified: the social expectation and prestige associated with classic models of clinical performance; the reception of an overload of work in territories of great extension; and the need to elaborate positions that counterpoint and complement the biomedical model.

Keywords: Psychology, Health Systems, Primary Health Care, Professionalization, Basic Health Care.

\title{
Prácticas de Psicólogos en la Estrategia Salud de la Família: Poder Simbólico y Autonomía Profesional
}

\begin{abstract}
Resumen: A partir del enfoque cualitativo de investigación social en salud, el presente estudio discute la inserción de psicólogos en los servicios de atención primaria del Sistema Único de Salud, mediante la Estrategia Salud de la Familia (ESF). El objetivo del trabajo es analizar especificidades de la actuación de los psicólogos en dichos servicios, enfocando en las prácticas desarrolladas para reconocimiento y autonomía profesional. La técnica empleada para la construcción del material empírico fue la entrevista semiestructurada aplicada a 18 psicólogos con amplia experiencia en la atención y formación para la ESF. El referencial teórico adoptado se pauta en los conceptos de poder simbólico y habitus de la sociología de Pierre Bourdieu. También se reanudan elementos teóricos procedentes de la sociología de las profesiones. Como resultados, se identifican tensiones pertinentes a las luchas por autonomía profesional. Un habitus profesional se presenta como ilustrativo de las prácticas denominadas específicas y distintivas del psicólogo: el saber lidiar con conflictos interpersonales; ser agente problematizador y mediador en las relaciones interprofesionales; y tener la capacidad de reconocer procesos históricos constituyentes de las subjetividades y tramas relacionales. Algunos desafíos a la autonomía profesional son identificados: la expectativa social y prestigio asociados a los modelos clásicos de actuación clínica; la acogida de una sobrecarga de trabajo en territorios de gran extensión; y la necesidad de elaborar posicionamientos que hagan contrapunto y complemento al modelo biomédico.
\end{abstract}

Palabras clave: Psicología, Sistemas de Salud, Atención Primaria de Salud, Profesionalización, Atención Básica a la Salud.

\section{Introdução}

A Estratégia Saúde da Família (ESF) expressa o movimento de ampliação da rede assistencial no Sistema Único de Saúde do Brasil (SUS), por meio do fortalecimento de propostas de intervenção focadas na Atenção Primária à Saúde (APS). Nesse processo, as Unidades Básicas de Saúde (UBS) vêm se constituindo como novos espaços para o desenvolvimento de práticas profissionais. Com a criação dos Núcleos de Apoio à Saúde da Família, em março de 2008, com a Portaria Interministerial no 154 (Brasil, 2008) e sua atualização na Política Nacional de Atenção Básica, em setembro de 2017 (Brasil, 2017), passando a ser denominado Núcleo Ampliado de Saúde da Família e Atenção Básica (Nasf-AB), um conjunto de ocupações e profissões da saúde vem ganhando espaços para atuação, nos quais pode participar criativamente na produção de saberes e práticas. Não obstante, tais espaços são constituídos de relações interprofissionais permeadas por interesses e disputas visando reconhecimento e autonomia.

O conceito de autonomia profissional é aqui retomado em Freidson (1978), autor destacado no âmbito da Sociologia das Profissões, que, consoante Bosi (1996), demarca autonomia como sendo a capacidade 
de uma corporação avaliar e controlar, técnica e economicamente, o desenvolvimento do seu trabalho. Nas palavras de Freidson, (1978) "uma posição predominante na divisão do trabalho, de tal modo que logra o controle sobre a determinação da essência do seu próprio trabalho" (p. 83). Tal posição caracteriza uma independência no desenvolvimento de sua prática, em termos técnicos e também econômicos, sendo que a autonomia técnica - monopólio sobre áreas específicas de prática, intrinsecamente ligada à base cognitiva da sua formação - é preponderante no que tange à autonomia profissional (Bosi, 1996). Para a psicologia, a ESF tem se constituído, na atualidade, como uma das principais portas de entrada para os psicólogos no SUS, oportunizando maior acesso da população às práticas psicológicas. Análises acerca das experiências de trabalho de psicólogos na ESF vêm avançando significativamente (Camargo-Borges \& Cardoso, 2005; Dimenstein \& Macedo, 2012; Iglesias \& Avellar, 2016; Pitombeira, Xavier, Barroso, \& Oliveira, 2016). Porém é um campo que ainda demanda reflexões sobre a construção social das práticas profissionais, bem como a compreensão das formas como os profissionais são reconhecidos e como se posicionam na defesa de algumas marcas identitárias em suas práticas.

A construção de nosso objeto de reflexão se origina na inserção profissional de um dos autores no cotidiano da ESF, como psicólogo-residente e como docente em um programa de Residência Multiprofissional em Saúde da Família, em uma cidade de médio porte no Nordeste do Brasil. A análise se amplia com a experiência dos demais autores em diferentes ações e na práxis da pesquisa no cotidiano de distintos dispositivos da rede de saúde, ao que se soma um longo itinerário no âmbito da Saúde Coletiva, como campo de saberes e práticas. Nessas experiências, entramos em contato com os intensos embates e disputas no processo de trabalho multiprofissional desenvolvido na APS do SUS. Esse trabalho objetiva, assim, discutir as especificidades das práticas dos psicólogos na ESF, analisando-as no contexto das lutas por reconhecimento e autonomia profissional.

Para tanto, operacionalizamos algumas das proposições de Pierre Bourdieu $(2008,2011,2012)$ em sua teorização sobre os campos sociais e o poder simbólico que permeia os processos de construção social da realidade e das práticas dos diferentes grupos. Nessa perspectiva, a especificidade de uma prática é constituída e legitimada socialmente pela inserção histórica dos agentes e instituições em determinados campos sociais, configurando o que o autor chama de habitus. O que perpassa a noção de habitus, na problematização bourdieusiana, é a necessidade de indagar o lugar da cultura de pertença e das trajetórias de socialização na construção das práticas sociais dos sujeitos. O habitus, dessa maneira, é uma disposição cultivada, um conjunto de esquemas interiorizados, incorporados - inscritos no próprio corpo. Retrata a dimensão corporal de um aprendizado passado, fruto de socialização. Segundo Bourdieu (2011),

Os condicionamentos associados a uma classe particular de condições de existência produzem habitus, sistemas de disposições duráveis e transponíveis, estruturas estruturadas predispostas a funcionar como estruturas estruturantes, ou seja, como princípios geradores e organizadores de práticas e representações que podem ser objetivamente adaptadas ao seu objeto sem supor a intenção consciente de fins e o domínio expresso das operações necessárias para alcançá-los, objetivamente "reguladas" e "regulares" sem em nada ser o produto da obediência a algumas regras e, sendo tudo isso, coletivamente orquestradas sem ser o produto da ação organizadora de um maestro (p. 87).

O conceito de habitus está associado à ideia de uma subjetividade socializada, constituindo esquemas ou disposições para agir, pensar e sentir. Ajuda-nos, dessa maneira, a compreender e analisar as práticas profissionais dos psicólogos que atuam na ESF. A prática profissional, em nossa concepção, com seu leque de ações e representações, traduz de modo exemplar o habitus (a presença ativa de experiências passadas, sistema incorporado de esquemas de percepção, pensamento e ação, que garantem a conformidade e constância das práticas). No nosso caso, refletiremos sobre a constituição social de um habitus profissional da psicologia, o qual remete à história dessa ciência e profissão no contexto brasileiro (Antunes, 2007; Coimbra \& Leitão, 2003; Pereira \& Pereira Neto, 2003), especialmente nos espaços sociais criados pelas políticas públicas de saúde em anos recentes.

\section{Estratégia Saúde da Família e Psicologia}

Nas últimas décadas, a ESF empreendeu uma significativa reestruturação no modelo de atenção, 
visando tornar a APS o centro dos processos de cuidado em saúde, como porta de entrada dos serviços e como forma de buscar mais efetividade na resolução dos problemas de saúde da população brasileira (Andrade, Barreto \& Bezerra, 2006; Brasil, 1997; Camargo-Borges \& Cardoso, 2005; Dimenstein \& Macedo, 2012). A APS, como modelo de atenção, visa fortalecer o acesso aos serviços de saúde e a capacidade de acolhimento dos sistemas nacionais de saúde, a partir de uma atenção longitudinal e do incentivo à responsabilidade sanitária de serviços públicos, organizados em torno de territórios delimitados geograficamente (Andrade et al., 2006). A ESF, em sintonia com os modelos de APS, pretende ser a principal porta de acolhimento e estratégia de articulação da rede de serviços do SUS, tendo, dentre seus princípios, a integralidade do cuidado (Mattos, 2004).

A criação dos Nasf-AB teve como objetivo ampliar a abrangência das ações da ESF, aumentando o leque de serviços aos usuários. A Psicologia é preconizada como uma das opções para a área de saúde mental, constituindo-se como uma profissão de referência para prestar um apoio às equipes das UBS (Brasil, 2008). Os Programas de Residência Multiprofissional em Saúde da Família (RMSF) também têm se destacado como canais de ampliação da inserção de psicólogos e outras profissões no SUS. O papel ocupado pelos programas de Residência Multiprofissional em Saúde (RMS) é de extrema importância por fomentar uma aproximação entre teoria e prática (Brasil, 2006). Ademais, expressam um movimento de significativa resistência à hegemonia do paradigma biomédico e ao complexo médico-industrial no campo da formação em saúde (Dallegrave \& Kruse, 2008).

O modelo proposto pela ESF, no contexto brasileiro, tem colocado em pauta a formação dos profissionais e ocupações em saúde, as práticas e serviços desenvolvidos em equipes multiprofissionais, em diferentes contextos socioculturais. Tais experiências têm incentivado a produção acadêmica na interface entre os campos da Saúde Coletiva e da Psicologia visando à ampliação dos conceitos e práticas ligados aos processos de saúde-doença-cuidado, bem como à criação de currículos mais próximos da realidade dos serviços de saúde e reformulações nas estratégias formativas (Dimenstein \& Macedo, 2012; Pitombeira et al., 2016).

As experiências dos psicólogos nas políticas sociais passaram a ser estudadas mais sistematicamente, o que revela uma variedade de temas como: expansão das práticas psicológicas e ampliação do acesso da população (Conselho Federal de Psicologia, 2009, 2010; Macedo \& Dimenstein, 2011, 2012; Nepomuceno \& Brandão, 2011; Romagnoli, 2009; Spink, 2010), bem como sobre a participação da profissão nas atividades de apoio matricial (Iglesias \& Avellar, 2016). Contudo, como referido anteriormente, esse espaço é constituído por relações interprofissionais permeadas por interesses e disputas visando ao reconhecimento e à autonomia profissional. Os psicólogos que formam parte das equipes na ESF têm um cotidiano marcado por lutas e negociações em relação a sua especificidade profissional, seja na perspectiva de uma atuação direta junto aos usuários, seja na perspectiva de apoiador matricial. A análise de como a profissão vem se redefinindo para garantir sua permanência nesse campo de trabalho e sobre os modos distintos como a atuação profissional dos psicólogos vem sendo reconhecida nos diversos espaços de atuação abertos pela ESF é o esforço empreendido neste estudo.

\section{Percurso metodológico}

Este trabalho adota a perspectiva epistemológica do enfoque qualitativo de pesquisa em saúde. Nessa perspectiva, buscamos, mediante atos interpretativos, compreender sentidos e significados atribuídos às práticas desenvolvidas no cotidiano dos serviços de saúde. Tomando como referência as ideias de Uchimura e Bosi (2002) sobre qualidade e subjetividade na avaliação de serviços e programas de saúde, direcionamos este estudo na "busca do sentido dos fenômenos no espaço de intersubjetividade, ou melhor, no espaço do encontro entre a subjetividade que se inscreve na vivência dos informantes e na vivência do próprio pesquisador, através das compreensões e interpretações compartilhadas" (p. 1567).

A obtenção do material discursivo se deu por meio da realização de entrevistas semiestruturadas com dezoito psicólogos com experiência na formação e atenção à saúde na ESF. Para a escolha dos participantes, priorizamos entrevistar psicólogos inseridos em programas de RMSF nos municípios de Fortaleza e Sobral, por reconhecer a importância desse dispositivo de formação para a redefinição de referências para as práticas em saúde na ESF. No decorrer do trabalho de campo, visando a ampliar o diálogo com psicólogos inseridos na ESF de modos diversos, buscamos a participação de profissionais inseridos em Nasf-AB, nos mesmos municípios, e docentes de 
universidades públicas situadas em Fortaleza. Para isso, entramos em contato com dois profissionais de Nasf-AB indicados por participantes já entrevistados e buscamos o contato com dois professores de cursos de Psicologia ofertados por universidades públicas presentes nesses municípios. No total, realizamos catorze entrevistas individuais e duas entrevistas com duplas, totalizando dezoito participantes, sendo onze mulheres e sete homens. A realização das entrevistas em duplas foi uma alternativa proposta pelos participantes diante de dificuldades de tempo livre e de oportunidades de encontro surgidas. $\mathrm{O}$ fechamento amostral se deu pelo princípio de information power (Malterud, 2016), ou seja, a densidade necessária (ou acúmulo subjetivo) para responder à questão da pesquisa, uma vez que a tradição qualitativa se ocupa da profundidade da compreensão e não da extensão, com vistas à generalização dos achados.

As entrevistas tiveram duração média de sessenta minutos e abordaram temas como: os âmbitos de prática dos psicólogos; a caracterização do trabalho dos psicólogos(as) na ESF; as demandas ou necessidades sociais que chegam ao/à psicólogo(a); as estratégias desenvolvidas pelos profissionais visando ao reconhecimento e à valorização; os obstáculos nesse caminho para o reconhecimento e valorização profissional; os dilemas ético-políticos vivenciados; e os significados da experiência profissional na ESF para a trajetória profissional dos entrevistados.

A interpretação do material discursivo produzido nas entrevistas se orientou teoricamente pelas ideias de Paul Ricoeur (1989, 2009), filiando-se à tradição fenomenológico-hermenêutica. Nesse sentido, buscamos colocar em prática a proposição de uma hermenêutica do texto como obra aberta a apropriações. Na interpretação das entrevistas, primeiramente identificamos, como resultado da escuta das gravações e de leituras iniciais das transcrições das entrevistas, uma estrutura inicial de temas do material, que fez parte do que chamamos "interpretação conjectural inicial". Com o intuito de processar e efetuar a codificação dos textos das entrevistas e subsidiar a identificação dos temas e unidades de significação do material, utilizamos como ferramenta o software Atlas TI. Neste trabalho, discutiremos o material empírico que nos possibilitou analisar dois temas relevantes: a) a construção social de especificidades das práticas profissionais dos psicólogos; e b) estratégias de lutas por reconhecimento e autonomia profissionais. Todos os participantes entrevistados assinaram o Termo de Consentimento Livre e Esclarecido. A pesquisa foi aprovada pelo Comitê de Ética em Pesquisa da Universidade Federal do Ceará.

\section{Resultados e discussão}

Conforme aludido, dialogamos com profissionais portadores de uma vasta e privilegiada experiência de formação e atuação no campo de práticas investigado, o que enriqueceu bastante o material empírico construído mediante o emprego das entrevistas. A amostra da pesquisa foi construída intencionalmente para estabelecer diálogos com profissionais inseridos nas RMSF, professores do setor de estudo Saúde Coletiva em graduações em Psicologia e profissionais inseridos em Nasf-AB. O perfil dos participantes se caracteriza da seguinte forma: em termos de tempo de trabalho na ESF, a maioria tinha mais de dois anos de experiência - somente dois participantes não haviam atingido o tempo quinze meses. Quanto à formação acadêmica, um participante já tinha concluído doutorado em Psicologia; cinco já haviam concluído mestrado em Saúde Pública; três tinham mestrado em Saúde da Família e um mestrado em Psicologia; e outros dois estavam cursando mestrado em Saúde Pública. Desse conjunto, treze já haviam concluído residência multiprofissional em Saúde da Família (seis em Sobral e sete em Fortaleza). Quanto às experiências profissionais, dezessete já tinham trabalhado como psicólogos da APS do SUS, e sete tiveram experiências profissionais de ensino em saúde direcionado à atuação na ESF sendo dois em cursos na graduação e cinco em programas de RMSF (três em Sobral e dois em Fortaleza). A análise do material produzido nas entrevistas foi dividida em dois grandes tópicos: a) Especificidades das práticas dos psicólogos; e b) Lutas por reconhecimento e autonomia profissional.

\section{Especificidades das práticas dos psicólogos}

Identificar os modos como são reconhecidas as especificidades das práticas dos psicólogos facilita a análise de processos sociais que permeiam as distinções valorativas da profissão diante das demais profissões inseridas na ESF. Destacaram-se certos signos característicos das práticas profissionais da psicologia que apontam para lutas simbólicas em que estavam inseridos. Tais lutas simbólicas tinham o intuito de definir ou 
redefinir seu objeto de atuação, visando a reconstruir visões restritivas da profissão, que acabavam por impor limites à autonomia profissional dos entrevistados.

Nesse contexto, a análise das entrevistas revela a recorrente identificação da psicologia como uma profissão que se diferencia das demais, marcada por um olhar sensível e uma escuta qualificada em termos dos processos subjetivos e intersubjetivos, e por ser capaz de intervir de modo mais competente no âmbito das relações interpessoais e de trabalho. Os psicólogos e psicólogas, como pudemos analisar, são reconhecidos pela capacidade de lidar com aspectos afetivos e subjetivos dos processos de saúde-doença-cuidado. À profissão é atribuída uma visão privilegiada sobre os fatores interpessoais envolvidos nos processos de trabalho em equipes multiprofissionais, na promoção do cuidado. A prática dos psicólogos, é reconhecida como capaz de compreender a constituição histórica de relações entre agentes, instituições e territórios. Todos esses atributos, construídos socialmente, fazem da psicologia uma profissão diferenciada e valorizada mediante outras na ESF. Como indicada abaixo, a distinção ou o caráter singular (e valorizado enquanto tal) da prática psicológica é sua preocupação com os processos intersubjetivos.

Ele [psicólogo] traz esse olhar, ele chama pra olhar subjetivamente os processos. ... Eu acho que ele se diferencia por isso, assim, de estar fazendo esse olhar subjetivo sobre essas questões todas, que perpassam a relação do usuário com a comunidade, relações institucionais (Entrevistado 4).

Essa escuta e olhar tornam a Psicologia uma profissão estratégica na elaboração e condução de alguns processos de cuidado específicos, que envolvem de modo intenso a dimensão subjetiva e as características singulares dos encontros cotidianos nos territórios da ESF. Baseando-nos em nossas entrevistas, entendemos que as especificidades da atuação profissional se situariam na convocação dessa dimensão do sujeito, da criação de possibilidades de sua elaboração, pela criação de canais de diálogo que facilitem a expressão de afetos e sofrimentos. Como destaca um dos participantes: "Assim, nesse sentido que cabe ao psicólogo compreender o tempo de cada sujeito. E eu acho que ele está ali, de alguma maneira, para convocar a singularidade desse sujeito frente aos discursos que são hegemônicos nas práticas de saúde" (Entrevistado 12).
Um agir "problematizador" e "mobilizador" também caracteriza a prática psicológica. Capaz de criar condições de reflexão, fala e vivência sobre o que afeta os sujeitos, a prática profissional intervém de forma intensa na trama relacional, que perpassa a maioria dos casos. A profissão, voltada para intervir nos processos subjetivos e intersubjetivos pertinentes à ESF, destaca-se ao apresentar certas categorias de percepção distintas, no que tange ao olhar e à intervenção nos territórios de saúde. A Psicologia é concebida socialmente como uma profissão que tem maior capacidade de compreender, analisar e intervir, sobretudo, nos casos em que o sofrimento e as demandas socioafetivas tendem a se exacerbar. Obtendo o reconhecimento social de seu poder diante do objeto "subjetividade”, os psicólogos e psicólogas passam a ser valorizados. À luz da perspectiva teórica de Bourdieu (2008, 2011, 2012), sobretudo em sua reflexão sobre o poder simbólico que permeia as relações sociais, podemos reconhecer as práticas profissionais atravessadas por lutas que visam à produção de visões de mundo legitimadas. Assim, a construção social das práticas profissionais é permeada pelas disputas por poder e capital simbólico, em que os profissionais se veem inseridos em espaços sociais hierarquizados e conflituosos. Interessa-nos, aqui, considerar a posição do agente (em nosso caso, o espaço ocupado pelo profissional psicólogo no campo da ESF) e seu capital simbólico acumulado em lutas anteriores, para destacar a histórica construção social de uma vinculação das práticas psicológicas ao objeto "subjetividade", bem como de uma via ambivalente de reconhecimento profissional que a vinculação favorece.

Revela-se, pois, um desafio importante à construção das práticas profissionais: por um lado, consolida a ideia de "especialista em processos subjetivos", aumentando seu poder de reconhecimento e valorização dentro do espaço sócio profissional. Esse reconhecimento é maximizado pela hegemonia da biomedicina e seu objetivismo, que impulsiona a reprodução de práticas limitadas e ineficientes diante de uma forte demanda de atendimento humanizado e cuidado integral. Assim, as lacunas deixadas pelo modelo biomédico impulsionam a construção do manejo do objeto "subjetividade", como exclusivo da psicologia. Por outro lado, a força do objeto de intervenção legitimado pede o reconhecimento da singularidade e a convocação da presença ativa de profissionais e usuários na produção de certas práticas. 
O profissional se vê diante da necessidade de atuar na desconstrução de definições fechadas sobre a profissão e engessamentos teórico-metodológicos que possam enrijecer o processo criativo necessário a cada prática singular, de modo a prosseguir legitimando o lugar ocupado pelas práticas nos serviços de saúde. Tal paradoxo da prática psicológica foi expresso por vários dos participantes, como na frase: "A gente está falando de qual é a especificidade da Psicologia, e a especificidade da Psicologia é se esvaziar do discurso do especialista" (Entrevistado 12).

Outro relevante aspecto, destacado em algumas das entrevistas, é que a psicologia, na relação com os usuários dos serviços, deve se constituir como uma profissão comprometida com a construção de saberes marcados pela experiência vivida dos indivíduos nos seus diversos cenários socioculturais. Assim, destacaram-se as falas que defendiam uma prática psicológica plural e distanciada dos "especialismos". O "especialismo psicológico", como fruto histórico da divisão social do trabalho, é responsável por agenciamentos implicados com a produção de hegemonias em termos das subjetividades. Nesse contexto, a psicologia tem, historicamente, contribuído para a construção de uma cultura individualista e psicologizadora dos problemas sociais (Coimbra \& Leitão, 2003; Macedo \& Dimenstein, 2012). Para Coimbra e Leitão (2003) "a crença nas essências produz a reificação do indivíduo" (p. 12). Essa reificação do indivíduo perpassa a constituição histórica de uma psicologia privatista, intimista e familiarista, integrada ao desenvolvimento sociocultural do capitalismo e incumbida de naturalizar e normatizar um "modo-de-ser indivíduo". Assim é que a Psicologia vem se constituindo, historicamente, como um equipamento social voltado para a psicologização da vida social (Coimbra \& Leitão, 2003).

Desse modo, identificamos que a construção das práticas dos psicólogos na ESF se efetiva em face dessa contraditória demanda. Por um lado, tem que lutar por legitimar sua atuação - ampliando o domínio sobre um saber específico, que lhe possibilita maior autonomia técnica (Bosi, 1996; Dubar, 2005; Machado, 1995). Por outro, agir como facilitador na construção de saberes sobre a saúde e o sofrimento mais plurais e decorrentes de outros modos de produção de subjetividade, visando à quebra dos especialismos psicológicos e à construção de uma psicologia politicamente situada na ESF. Bourdieu (2012), ao tratar das lutas simbólicas, possibilita-nos analisar os embates que permeiam a construção de identidades sociais, dentre as quais se situa a identidade profissional. Para o autor, a construção social da realidade é marcada pela economia das trocas simbólicas que envolve estratégias de dominação simbólica na construção do mundo social. Nessa economia, as lutas envolvem, entre outras questões:

a conservação ou a transformação das leis de formação dos preços materiais ou simbólicos ligados às manifestações simbólicas (objetivas ou intencionais) da identidade social. Nesta luta pelos critérios de avaliação legítima, os agentes empenham interesses poderosos, vitais por vezes, na medida em que é o valor da pessoa enquanto reduzida socialmente à sua identidade social que está em jogo (Bourdieu, 2012, p. 124).

A busca pela autonomia, nessa perspectiva, consiste no esforço de poder "definir os princípios de definição do mundo social em conformidade com os seus próprios interesses" (Bourdieu, 2012, p. 125). Remete à apropriação de vantagens simbólicas atreladas à posse de uma identidade publicamente afirmada e reconhecida, bem como da liberação do julgo e avaliação sob critérios desfavoráveis. É nesse processo de luta para impor uma visão de mundo e, mais especificamente, para definir a especificidade do fazer do psicólogo, que ele é chamado a intervir em problemas de saúde e ter seu reconhecimento associado a uma modalidade específica de prática. Na perspectiva dos participantes da pesquisa, muitas das especificidades atribuídas à prática do psicólogo não condizem com o caminho de intervenção apropriado ao fazer da Psicologia.

O lugar de distinção da Psicologia é difícil de ser percebido por alguns dos entrevistados, seja por insegurança em se definir como um profissional com objetos imprecisos, seja pelo aprisionamento que a definição do objeto acaba por instituir. Ademais, os movimentos empreendidos pelos profissionais, no sentido de delimitar um espaço específico de atuação, esbarram no desafio de criar um agir profissional mais autônomo, diante dos modelos tradicionais de atuação profissional.

Eu não saberia dizer o que é específico ao psicólogo. Na verdade, eu tenho receio de dizer isso. Eu tenho receio de dizer o que é específico. Eu tenho receio de criar esse campo de poder que, por sinal, já está 
criado. E que, às vezes, me maltrata. ... Porque, o que é específico do psicólogo? Na verdade, a gente está ampliando cada vez mais, pra ver se a gente cria possibilidade de respirar e de criar algo novo (Entrevistado 8).

Nesse contexto de definição de especificidades profissionais da Psicologia, há uma busca por identificar e defender estratégias de formação/graduação, para a consolidação de um fazer psicológico distinto, em sintonia com os interesses das várias áreas de atuação profissional. Observamos que, dentro da lógica das lutas simbólicas, os participantes da pesquisa se esforçaram em participar ativamente da definição do que é o "essencial" da prática profissional. Assim, deparamos com a identificação de outras marcas distintivas: o olhar clínico do profissional psicólogo e sua atuação junto aos processos grupais das equipes multiprofissionais. Ambos se tratam de modos específicos de atuar que, como abordado em algumas entrevistas, são constituídos ou influenciados pela formação profissional. Entendemos que tais saberes-fazeres específicos da profissão têm contribuído para o reconhecimento da Psicologia nos Nasf-AB, pelas potencialidades de intervenção com a população e/ou na perspectiva do matriciamento junto às UBS, ampliando a visão e atuação dos profissionais diante dos problemas de saúde mental contextualizados nos territórios, conforme destacam pesquisas recentes (Iglesias \& Avellar, 2016; Leite, Andrade, \& Bosi, 2013; Oliveira, Amorim, Oliveira, Nascimento, \& Araújo, 2017).

No que diz respeito ao olhar clínico do psicólogo, este visa a subsidiar um conjunto de ações pautadas numa relação terapêutica diferenciada entre usuários e profissionais, capaz de reconhecer a história e constituição das individualidades nos territórios de atuação da ESF, com a já abordada habilidade de lidar com os processos subjetivos.

Então, eu acho que específico seria esse olhar diferenciado da relação da constituição do indivíduo, no lugar que ele vive. E, nessa parte da avaliação e do acompanhamento, tem mesmo esse aspecto dos conhecimentos da clínica e da psicoterapia, que ajudam nessa relação terapêutica diferenciada.... Eu acho que os conhecimentos da clínica permitem que a gente tenha uma relação terapêutica, um outro olhar. Então, no fundo, eu acho que o que é específico do psicólogo é o olhar clínico (Entrevistado 2).
Acerca da especificidade da prática dos psicólogos nos processos grupais, observamos que à Psicologia é atribuída a competência de agir de modo qualificado no processo de trabalho em equipe, especialmente na mediação de relações interpessoais em pequenos e grandes grupos multiprofissionais atuando dentro das equipes e, também, no relacionamento entre equipes. Nesse contexto, notamos forte congruência entre a especificidade da prática dos psicólogos, tal como reconhecida por eles, e as prerrogativas da prática dos Nasf-AB, conforme preconizadas pela PNAB (Brasil, 2017), para uma intervenção prioritariamente de matriciamento. Nesse contexto, o adjetivo de "mediador" é, sobremaneira, atribuído aos psicólogos, que encontram espaço privilegiado para atuações no cotidiano de trabalho na ESF, seja para superar crises relacionais entre profissionais, seja para repensar a atuação em casos difíceis. Os atributos de "mediador de conflitos" e "solucionador de casos difíceis" constituem parte da representação social do psicólogo no campo e implica na criação de extensas demandas para as práticas clínicas da profissão - ligadas a uma importante expectativa social em torno da profissão.

Eu sei que esse é o lugar que as outras categorias colocam o profissional de psicologia: mediador. O psicólogo é o que vai, por exemplo, mediar um conflito dentro da própria equipe. ... O psicólogo é colocado como esse cara ou essa pessoa que vai conseguir abrir caminhos (Entrevistado 5).

Entrelaçando alguns temas pertinentes às entrevistas, podemos destacar que o diferencial das práticas dos profissionais da Psicologia na ESF, como destacado pelos participantes, é a capacidade, desenvolvida em formação específica, para entender de modo ampliado a constituição dos processos subjetivos referentes a pessoas e grupos, reconhecendo a dimensão subjetiva inerente à construção das práticas de saúde, dos estilos de vida, dos processos de cuidado e de adoecimento. Essa capacidade de atuação junto aos processos subjetivos pode ser interpretada à luz do conceito de habitus (Bourdieu, 2012; Wacquant, 2007). Assim, podemos identificar um conjunto dinâmico de disposições sobrepostas e incorporadas nos processos de socialização que se relacionam à formação dos psicólogos e sua preparação para os campos de atuação. Esse habitus profissional se expressa em um tipo de escuta (psico)terapêutica, em um tipo 
de olhar voltado aos processos subjetivos. São constituídas socialmente práticas distintivas que se voltam para os processos de trabalho em saúde e têm por finalidade, entre outras, o resgate da dimensão subjetiva do adoecimento e da saúde e a mediação de conflitos interpessoais. A constituição histórica e intersubjetiva dos problemas de saúde (individuais e coletivos) é um dos objetos de sua reflexão prática, ponto de partida para a construção de saberes e práticas dos psicólogos na ESF.

O processo de formação, marcado por experiências em Psicologia Clínica, Psicologia Social e Psicologia Comunitária, somadas ao exercício de uma escuta terapêutica e de compreensão do sujeito e sua história de vida e de inserção social, marca a constituição social de um modo específico de agir que é reconhecido pelos participantes da pesquisa. Essa atribuída habilidade prática, aprendida socialmente, de compreender os processos de constituição dos sujeitos como agentes históricos com trajetórias de vida singulares, pode se expressar em diversas práticas desenvolvidas pelos profissionais psicólogos. Nesse contexto, as práticas caracterizadas como específicas aos psicólogos, ou que são desenvolvidas por estes, foram: a prática da clínica psicológica em saúde mental; a intervenção que visa a fortalecer o trabalho coletivo e interprofissional em equipes do território; o atendimento de "casos difíceis", que necessitem de maior adesão aos tratamentos e maior comprometimento de usuários e família; e a facilitação de grupos diversos. Tais informações referentes às modalidades de prática corroboram outros estudos desenvolvidos no âmbito da discussão das áreas de intervenção (Cezar, Rodrigues, \& Arpini, 2015; Marques \& Oliveira, 2015; Nepomuceno \& Brandão, 2011). Destacamos a lógica social que permeia a reprodução de modalidades práticas a partir da defesa de um objeto de intervenção - subjetividade ou processos subjetivos - e que é parte da configuração das lutas por reconhecimento profissional em um campo hierarquizado e plural. É esse espaço socioprofissional desigual e conflituoso, como abordado por Nepomuceno e Pontes (2017), que se constituirá como cenário para a participação da psicologia na PNAB (Brasil, 2017) e programas de RMSF.

Quando analisamos as ações reconhecidas como específicas da Psicologia, alguns atributos ganharam destaque. Dentro desse contexto, a escuta individual, a partir de uma perspectiva de atendimento clínico psicológico, destaca-se como um tipo de "procedimento padrão da classe", como uma marca da categoria. Tal prática foi identificada como aquela capaz de garantir e legitimar a presença do profissional nas equipes da ESF, configurando-se como uma distinção valorativa que expressa certo protagonismo da Psicologia no espaço das lutas por reconhecimento e autonomia profissional. Desse modo, o próprio habitus profissional se consolida nas relações de troca que permeiam a construção social das demandas que "chegam" aos profissionais da Psicologia.

A clínica psicológica, na percepção dos entrevistados, confirma o imaginário social construído historicamente em torno da profissão e constitui-se como um conjunto de práticas ambivalentes no contexto das lutas por autonomia profissional. Sendo presente nas análises sobre o processo de trabalho dos participantes, a clínica psicológica se desenvolveu atravessada pela permanente tensão e negociação para definir o que era e o que não era legítimo de se fazer na ESF. Nas experiências vividas pelos participantes, a psicologia luta para desconstruir uma concepção de que seu trabalho específico e distintivo só se efetiva verdadeiramente no consultório, no atendimento clínico, no tratamento de transtornos mentais e na clínica da singularidade. No contexto da nossa pesquisa, foi notável a existência de excesso de demandas clínicas em saúde mental para os psicólogos. Em diversos cenários de prática da ESF, o psicólogo é reconhecido como um dos profissionais mais habilitados para lidar com o sofrimento humano.

Além do sofrimento, a Psicologia, com seu olhar "específico" para a singularidade, vai construindo um amplo leque de possibilidades de intervenção de acordo com as situações e brechas na estrutura da ESF. O sofrimento se configura, muitas vezes, a depender da força criativa e micropolítica do profissional, como um primeiro passo para a estruturação de diversas práticas que podem envolver as perspectivas da prevenção e tratamento de doenças e agravos, promoção e educação em saúde, entre outras perspectivas de cuidado voltadas para o amplo espectro da atenção integral à saúde.

Podemos, aqui, entender as profissões como resultantes de processos sociais de luta e legitimação, que expressam o maior ou menor avanço dos processos de profissionalização (Bosi, 1996; Machado, 1995) e a garantia ou não de um espaço legitimado de atuação, que se reflete diretamente na construção de uma identidade profissional (Dubar, 2005). É parte 
desses processos de luta interprofissional, retomando as ideias de Bourdieu (2012) sobre o poder simbólico, a busca por maior reconhecimento e legitimação no que tange à capacidade de nomear e classificar o mundo social, a partir de princípios de visão e divisão favoráveis à profissão. Nesse sentido, a crença na Psicologia e em sua capacidade de lidar com as dimensões subjetivas dos fenômenos humanos, além do capital simbólico que representa, também expressa um conjunto de estigmas para a profissão, responsáveis pela criação de demandas problemáticas e restritivas. Apesar de certos constrangimentos causados pela exacerbação da especialidade do saber psicológico, transformado em estereótipo e repercutindo na construção de demandas problemáticas, há um conjunto de consensos que colocam a prática da Psicologia, em contraponto com o modelo biomédico, em um lugar de reconhecimento e exaltação pelo fato de saber lidar, de modo protagonista, com a dimensão subjetiva dos processos de adoecimento, do cuidado e promoção da saúde, bem como com um conjunto de questões intersubjetivas que perpassam a produção das práticas multiprofissionais nesse campo. Abrem-se, a partir desse reconhecimento, muitos espaços que podem ser ocupados pelos profissionais.

\section{Armadilhas do reconhecimento e desafios para a autonomia profissional}

No intuito de abordar alguns dos desafios colocados pela ESF à inserção das práticas profissionais da Psicologia, precisamos nos voltar aos modos como as profissões são reconhecidas. Nesse intuito, perguntamos aos participantes deste estudo como a Psicologia era reconhecida como profissão dentro desse espaço de atuação profissional. Os diálogos realizados nas entrevistas nos ajudaram a identificar vários desafios enfrentados e estratégias de luta criadas visando a ampliar a autonomia profissional. Destacamos, como aspecto marcante do material analisado, uma ambivalente forma de reconhecimento profissional: uma extensa demanda de trabalho para a psicologia na ESF. Por um lado, a demanda se apresenta como uma forma de visibilidade e notoriedade alcançada pela profissão. Por outro lado, essa intensa procura pela profissão nos CSF expõe uma armadilha que aprisiona os profissionais numa incômoda sobrecarga de trabalho marcada, sobretudo pela expectativa do atendimento clínico individual - como procedimento que representa socialmente o fazer psicológico.
A gente começava a perceber um excesso de demandas: "fulano tem transtorno", "fulano é estranho", "fulano tem algum problema", "atenda". E aí, quando a gente começava a investigar o que realmente estava por trás dessas queixas ... a gente começava a perceber que tinham situações sociais por trás (Entrevistado 5).

Em todas as entrevistas realizadas, foi possível analisar que as práticas clínicas de atendimento ambulatorial dos psicólogos eram hipervalorizadas pelos demais profissionais da ESF e pela população em geral. Os profissionais entrevistados relataram a necessidade de dizer "não" às expectativas dos outros agentes, mas acolher as demandas trazidas e buscar a legitimação de práticas desconhecidas ou percebidas como "ineficientes" ou “impróprias".

Para ser reconhecido e valorizado na ESF, o psicólogo tem que acolher o que as pessoas trazem, ele tem que acolher e não pode dizer simplesmente "não" e ficar lá todo tempo dizendo o que ele não faz. Ele tem que acolher, até porque aquela pessoa não tem obrigação nenhuma de saber o que ele faz e o que ele não faz. Então ele tem que acolher isso e, também, ler o que está por trás dos pedidos (Entrevistado 4).

Existem diversas estratégias apontadas pelos participantes da pesquisa para superar os obstáculos colocados no cotidiano da ESF para a obtenção de reconhecimento. Uma delas diz respeito ao processo de acolhimento de demandas, mesmo que ligadas a estereótipos da profissão. Aqui, passa a ser relevante o processo de leitura crítica, tradução e transformação das demandas, que deve se constituir da delimitação de um espaço distinto de práticas.

$\mathrm{O}$ enfrentamento de uma hierarquia de poder instituída no cotidiano das práticas, que valoriza os saberes biomédicos percebidos como mais legitimados científica e socialmente, é outro desafio ao qual os profissionais da Psicologia precisam ter de se adaptar, engajando-se nas lutas por espaço e legitimação. Nesse contexto, a experiência dos participantes nos ajudou a entender nuances das relações de força instituídas no campo.

Eu tenho a impressão que ainda tem uma hierarquia regulada por essa hegemonia da Medicina, 
enquanto a profissão de ponta ainda desses espaços, muito embora o campo, ele tenha se constituído, enfim, a partir de uma crítica a essa hegemonia. E eu acho que ele não conseguiu ainda se livrar dela (Entrevistado 12).

Nesse aspecto, a Psicologia se engaja em negociações que permeiam a ocupação de espaços contraditórios de prestígio e submissão, condição que faz parte da sua história. A história da psicologia no Brasil é marcada por uma relação de cooperação e, por vezes, submissão à medicina e à psiquiatria tradicional (Antunes, 2007; Pereira \& Pereira Neto, 2003). Assim, a relação com o modelo biomédico é estruturante de várias práticas profissionais da Psicologia, especialmente no campo das práticas em saúde e saúde mental. É notável, nesse contexto histórico da saúde, uma participação da Psicologia como ciência implicada com as questões que envolvem o controle de corpos e mentes, na perspectiva da medicina social higienista (Antunes, 2007; Figueiredo \& Santi, 2010). Assim, ao discutir o reconhecimento e valorização da Psicologia na ESF, deparamos com o desafio que historicamente vem se constituindo e se reproduzindo, a saber: o enfrentamento do modelo biomédico como estruturador de relações de força e dominação no espaço socioprofissional dos serviços de saúde.

Ser reconhecido, para alguns entrevistados, significa ser competente no desenvolvimento de suas práticas "específicas", voltadas para o manejo de processos subjetivos já abordados anteriormente, constituindo-se como profissional articulador e mediador das ações nas equipes multiprofissionais. Como destaca o entrevistado 7: “o profissional da Psicologia vai sendo importante e, muitas vezes, fundamental como um grande articulador, como alguém que entende da subjetividade, valoriza, respeita e sabe trabalhar com alguns recursos". Agindo dentro de "seu" núcleo específico de práticas, o profissional pode obter a valorização de suas práticas alcançando um espaço de visibilidade e poder. Além dessas habilidades profissionais ditas e concebidas socialmente como específicas, é preciso "provar publicamente" que as práticas profissionais dos psicólogos (diversas, muitas vezes, do que se espera delas) são resolutivas no enfrentamento dos problemas de saúde trabalhados no cotidiano. É preciso ser resolutivo para ter reconhecimento e valorização profissional.
Alguns obstáculos foram identificados com certa regularidade, apresentando desafios para o desenvolvimento das práticas profissionais, como a necessidade de saber lidar com a extensa demanda para o atendimento clínico da psicologia. Aqui, destaca-se o imperativo de criar estratégias que imponham limites e mecanismos de adequação para tais demandas, bem como a necessidade de desenvolver atividades de matriciamento sintonizadas com o que preconiza os Nasf-AB (Brasil, 2017). O distanciamento histórico da formação em Psicologia para a atuação nas políticas públicas de saúde também é outro obstáculo a ser superado pelo profissional, o que remete à importância do fomento de estratégias educacionais durante e após a graduação em Psicologia. A RMSF foi elogiada pelos participantes desta pesquisa como proposta alternativa importante para suprir as lacunas deixadas pela graduação, instrumentalizando os profissionais para uma atuação mais potente na APS do SUS. No entanto, na busca pelo reconhecimento da Psicologia na ESF, é preciso conquistar espaços nos próprios sistemas municipais em que a RMSF se desenvolveu.

Vários desses obstáculos derivam da precariedade do campo da ESF para os profissionais inseridos em equipes de apoio, no modelo dos Nasf. Os vínculos trabalhistas precários colocam os profissionais em situação de vulnerabilidade diante das gestões municipais e de instabilidade no emprego, o que convoca o profissional a entrar em um estado de permanente tensão e busca de outras possibilidades de trabalho mais estáveis, como nos cargos abertos em concursos. Essa precariedade também se reflete na ampla área de responsabilidade sanitária, ou território de adstrição de clientela, para atuação destinada aos profissionais entrevistados.

A reformulação de um conjunto de práticas tradicionais e sua integração a uma representação social da profissão entendida como equivocada é apontada pelos participantes. Por mais que isso envolva um conjunto de lutas em torno da definição legítima das práticas da APS e da Psicologia, essa reconstrução da identidade profissional é um fenômeno transversal a todo um conjunto de estratégias, que visam à ampliação do poder da Psicologia para atuar de modo mais amplo e autônomo, no sentido de ocupar espaços de maior legitimidade no campo de práticas, para além do espaço já conquistado historicamente do consultório. Nesse contexto, é preciso refletir sobre o espaço social da ESF como território de lutas simbólicas, 
em que as práticas dos psicólogos devem se constituir com certa rebeldia diante do já está instituído que tem forte poder instituinte.

Eu acho que a gente tem que ser um pouquinho mais rebelde com algumas coisas, que a gente ainda é uma profissão muito tutelada, pelo o que se espera que a gente faça. Eu acho que tem que ser mais rebelde com a equipe mínima, tem que ser mais rebelde. E o que eu estou chamando de rebeldia équestionar algumas coisas que já estão estabelecidas e cristalizadas nas práticas de trabalho.... Nós temos algum valor no que fazemos e precisamos aprender como dizer isso de forma um pouco mais clara pros nossos usuários e para as pessoas que trabalham com a gente.... A gente tem que ser mais rebelde e não estar muito esperando ser convidado para a festa, sabe? (Entrevistado 16).

De acordo com a fala do participante, o reconhecimento e valorização da Psicologia remetem a uma postura ativa e transformadora do campo de práticas, rebelde diante da passividade com que os processos de trabalho, muitas vezes, impõem uma visão equivocada e restritiva no âmbito das práticas profissionais. Em nossa análise, para um melhor posicionamento da Psicologia no contexto de lutas por reconhecimento e autonomia profissional na ESF, é necessária a implicação de agentes individuais e coletivos da Psicologia em uma reflexão capaz de apreender os processos sociais e históricos que permeiam a definição das práticas profissionais e facilitar uma atualização do seu arcabouço teórico e técnico na perspectiva de reinventar a profissão e seu compromisso social.

\section{Considerações finais}

A construção social das especificidades das práticas profissionais dos psicólogos deve ser analisada como um esforço coletivo de luta e resistência simbólica mediante as visões hegemônicas e cristalizadas da ESF e da Psicologia, visando à instauração de mudanças e reinvenções nos modos de atuação profissional.
Novamente, destacamos a dimensão simbólica das mudanças que se colocam como necessárias à construção de práticas mais autônomas e contextualizadas socialmente.

A análise das especificidades das práticas psicológicas nos leva a conhecer os modos como a Psicologia é construída simbolicamente no espaço social da ESF. Acessando uma rica experiência acumulada de trabalho na ESF, no diálogo com nossos participantes, vislumbramos alguns dos processos de construção social que permeiam a configuração de um habitus profissional voltado para intervenções que tinham como objeto a subjetividade ou os processos subjetivos e intersubjetivos. As especificidades atribuídas às práticas desenvolvidas revelam uma posição importante no espaço socioprofissional da ESF, estabelecendo um contraponto e um complemento ao modelo biomédico na construção do cuidado em saúde. As práticas dos psicólogos encontram no atendimento clínico individual uma das formas de se distinguir e se valorizar nas lutas simbólicas estabelecidas, revelando a ambivalente condição de ter que lidar com grandes demandas e expectativas: Por um lado, a valorização e o reconhecimento profissionais de quem é publicamente aceito como relevante para a ESF; por outro, a incômoda condição de ter que lidar com expectativas dos outros, que aprisionam o sentido das práticas.

Na perspectiva das lutas por reconhecimento e ou mesmo revolução simbólica necessária, para reafirmar o diálogo com a perspectiva teórica bourdieusiana, as práticas profissionais desenvolvidas por psicólogas e psicólogos devem apontar para a afirmação de novos horizontes éticos, políticos e epistemológicos efetivos diante das necessidades de saúde da população e do processo de constituição e legitimação de espaços mais qualificados que expressem maior autonomia profissional. A atuação profissional da Psicologia, no contexto das relações de poder simbólico construídas na ESF, precisa ser compreendida em uma conjuntura social marcada por disputas entre o tradicional e o novo, entre ortodoxia e heterodoxia. É nessa conjuntura que novos e velhos posicionamentos se (re)produzem.

\section{Referências}

Andrade, L. O. M., Barreto, I. C. H.C., \& Bezerra, R. C. (2006). Atenção Primária à Saúde e Estratégia de Saúde da Família. In G. W. S. Campos, M. C. S.Minayo, M. Akerman, M. Drumond Júnior, \&Y. M. Carvalho (Orgs.), Tratado de saúde coletiva (pp. 783-836). Hucitec.

Antunes, M. A. M. (2007). A Psicologia no Brasil: Leitura histórica sobre sua constituição. Unimarco Editora. 
Nepomuceno, L. B., Bosi, M. L. M., Dimenstein, M., \& Pontes, R. J. S. (2021). Práticas de Psicólogos na Estratégia Saúde da Família.

Bourdieu, P. (2008). Para uma sociologia da ciência. Edições 70.

Bourdieu. P. (2011). Economia das trocas simbólicas (7a ed.). Perspectiva.

Bourdieu, P. (2012). Poder simbólico (16a ed.). Bertrand Brasil.

Bosi, M. L. M. (1996). Profissionalização e conhecimento: A nutrição em questão. Hucitec.

Brasil. (1997). Saúde da Família: uma estratégia para a reorientação do modelo assistencial. Ministério da Saúde.

Brasil. (2006). Residência multiprofissional em saúde: Experiências, avanços e desafios. Ministério da Saúde..

Brasil. (2008). Portaria no 154, de 24 de janeiro de 2008. Núcleos de apoio à saúde da família.http:/ / dab.saude.gov.br/ docs/legislacao/portaria154_24_01_08.pdf

Brasil. (2017). Portaria no 2.436, de 21 de setembro de 2017. Política Nacional de Atenção Básica. http://bvsms.saude. gov.br/bvs/saudelegis/gm/2017/prt2436_22_09_2017.html

Camargo-Borges, C., \& Cardoso, C. L. (2005). A psicologia e a estratégia saúde da família: Compondo saberes e fazeres. Psicologia \& Sociedade, 17(2), 26-32. http:/ http://www.scielo.br/pdf/psoc/v17n2/27041.pdf

Cezar, P. K., Rodrigues, P. M., \& Arpini, D. M. (2015). A psicologia na Estratégia de Saúde da Família: Vivências da residência multiprofissional. Psicologia: Ciência e Profissão, 35(1), 211-224. http://dx.doi.org/ $10.1590 / 1982-3703000012014$

Coimbra, C., \& Leitão, M.B.S. (2003). Das essências às multiplicidades: Especialismo Psi e produções de subjetividade. Psicologia \& Sociedade, 15(2), 6-17. http://dx.doi.org/10.1590/S0102-71822003000200002

Conselho Federal de Psicologia. (2009). A prática da psicologia e o núcleo de apoio à saúde da família. Edição Conselho Federal de Psicologia.

Conselho Federal de Psicologia. (2010). Práticas profissionais de psicólogos e psicólogas na atenção básica. Edição Conselho Federal de Psicologia.

Dallegrave, D., \& Kruse, M. H. L. (2008). No olho do furacão, na ilha da fantasia: A invenção da residência multiprofissional em saúde. Interface - Comunicação, Saúde, Educação, 13(28), 213-237. http://dx.doi.org/10.1590/ S1414-32832009000100018

Dimenstein, M., \& Macedo, J. P. (2012). Formação em Psicologia: Requisitos para a atuação em atenção primária e psicossocial. Psicologia: Ciência e Profissão, 32(num. esp.), 232-245. http://dx.doi.org/10.1590/ S1414-98932012000500017

Dubar, C. (2005). A socialização: Construção de identidades sociais e profissionais. Martins Fontes.

Figueiredo, L. C., \& Santi, P. L. R. (2010). Psicologia, uma (nova) introdução: Uma visão histórica da psicologia como ciência (3a ed.). Educ.

Freidson, E. (1978). La profisión médica: Un estudio de sociología del conocimiento aplicada. Península.

Iglesias, A., \& Avellar, L. Z. (2016). As contribuições dos psicólogos para o matriciamento em Saúde Mental. Psicologia: Ciência e Profissão, 36(2), 364-379. http://dx.doi.org/10.1590/1413-81232014199.00322013

Leite, D. C., Andrade, A. B., \& Bosi, M. L. M. (2013). A inserção da psicologia nos núcleos de apoio à saúde da família. Physis Revista de Saúde Coletiva, 23(4), 1.167-1.187. http://dx.doi.org/10.1590/S0103-73312013000400008

Macedo, J. P., \& Dimenstein, M. (2011). Expansão e interiorização da psicologia: Reorganização dos saberes e poderes naatualidade. Psicologia:CiênciaeProfissão,31(2),296-313.http://dx.doi.org/10.1590/S1414-98932011000200008

Macedo, J. P., \& Dimenstein, M. (2012). O trabalho dos psicólogos nas políticas sociais no Brasil. Avances en Psicología Latinoamericana, 30(1), 182-192. http://www.scielo.org.co/pdf/apl/v30n1/v30nla15.pdf

Machado, M. H. (1995). Sociologia das profissões: Uma contribuição ao debate teórico. In M. H. Machado (Org.), Profissões de saúde: Uma abordagem sociológica. Editora Fiocruz.

Malterud, K. (2016). Theory and interpretation in qualitative studies from general practice: Why and how? Scandinavian Journal of Public Health, 44, 120-129. http://dx.doi.org/10.1177/1403494815621181

Marques, A. A. D. V. \& Oliveira, R. W. (2015). Possíveis contribuições da psicologia na Estratégia de Saúde da Família: Interdisciplinaridade entre fazeres e saberes. Estudos Interdisciplinares em Psicologia, 6(2), 39-58. https://doi/org/ $10.5433 / 2236-6407.2015 \mathrm{v} 6 \mathrm{n} 2 \mathrm{p} 38$ 
Mattos, R. A. (2004). Integralidade na prática (ou sobre a prática da integralidade). Cadernos de Saúde Pública, 20(5), 1411-1416. http://dx.doi.org/10.1590/S0102-311X2004000500037

Nepomuceno, L. B. \& Brandão, I. R. (2011). Psicólogos na Estratégia Saúde da Família: caminhos percorridos e desafios a superar. Psicologia:Ciência e Profissão, 31(4), 762-777.http://dx.doi.org/10.1590/S1414-98932011000400008

Nepomuceno, L. B. \& Pontes, R. J. S. (2017). O espaço socioprofissional da Estratégia Saúde da Família sob a perspectiva de psicólogos. Psicologia: Ciência e Profissão, 37(2), 289-303. https://doi.org/10.1590/1982-3703000352015

Oliveira, I. F., Amorim, K. M. O., Paiva, R. A., Oliveira, K. S. A., Nascimento, M. N. C., \& Araújo, R. L. (2017). A atuação do psicólogo nos Nasf: desafios e perspectivas na atenção básica. Temas em Psicologia, 25(1), 291-304. http://dx.doi.org/10.9788/TP2017.1-17Pt

Pereira, F. M. \& Pereira Neto, A. (2003). O psicólogo no Brasil: Notas sobre seu processo de profissionalização. Psicologia em Estudo, 8(2), 19-27. http://dx.doi.org/10.1590/S1413-73722003000200003

Pitombeira, D. F., Xavier, A. S., Barroso, R. E. C., \& Oliveira, P. R. S. (2016). Psicologia e a formação para a saúde: Experiências formativas e transformações curriculares em debate. Psicologia: Ciência e Profissão, 36(2), 280-291. http://dx.doi.org/10.1590/1982-3703001722014

Ricoeur, P. (1989). Do texto à acção: Ensaio de hermenêutica II. Rés-Editora.

Ricoeur, P. (2009). Teoria da interpretação: O discurso e o excesso de significação. (A. Morão, Trad.). Edições 70.

Romagnoli, R. C. (2009). Breve estudo institucionalista acerca do Programa de Saúde da Família. Saúde e Sociedade, 18(3), 525-536. http://dx.doi.org/10.1590/S0104-12902009000300016

Spink, M. J. (2010). (Org.). A psicologia em diálogo com o SUS: Prática profissional e produção acadêmica. Casa do Psicólogo.

Uchimura, K. Y., \& Bosi, M. L. M. (2002). Qualidade e subjetividade na avaliação de programas e serviços em saúde. Cadernos de Saúde Pública, 18(6), 1561-1569. http:// dx.doi.org/10.1590/S0102-311X2002000600009

Wacquant, L. (2007). Esclarecer o habitus. Educação \& Linguagem, 10(16), 63-71. http://dx.doi.org/ 10.15603/2176-1043/el.v10n16p63-71

\section{Léo Barbosa Nepomuceno}

Professor doutor no Instituto de Educação Física e Esportes (Iefes) e do Programa de Pós-Graduação em Saúde Pública (PPGSP) da Universidade Federal do Ceará (UFC), Fortaleza - CE. Brasil.

E-mail: leobnepomuceno@hotmail.com

(1) https://orcid.org/0000-0002-7473-9460

\section{Maria Lúcia Magalhães Bosi}

Professora com pós-doutorado do Programa de Pós-Graduação em Saúde Pública do Departamento de Saúde Comunitária da Faculdade de Medicina da Universidade Federal do Ceará, Fortaleza - CE. Brasil.

E-mail:malubosi@ufc.br

(1) https://orcid.org/0000-0001-9742-9230

\section{Magda Dimenstein}

Professora com pós-doutorado do Programa de Pós-graduação em Psicologia do Departamento de Psicologia da Universidade Federal do Rio Grande do Norte, Natal - RN. Brasil.

E-mail: mgdimenstein@gmail.com

(1) https://orcid.org/0000-0002-5000-2915

\section{Ricardo José Soares Pontes}

Professor com pós-doutorado do Programa de Pós-Graduação em Saúde Pública do Departamento de Saúde Comunitária da Faculdade de Medicina da Universidade Federal do Ceará, Fortaleza - CE. Brasil.

E-mail: ripontesufc@gmail.com

(1) https://orcid.org/0000-0002-8976-4562 
Endereço para envio de correspondência:

Universidade Federal do Ceará, Instituto de Educação Física e Esportes. Av. Mister Hull, s/n. Parque Esportivo, Bloco 320, Campus do Pici. CEP: 60455-760. Fortaleza - CE. Brasil.

Recebido 28/12/2017

Aceito 12/06/2019

Received $12 / 28 / 2017$

Approved 06/12/2019

Recibido 28/12/2017

Aceptado 12/06/2019

Como citar: Nepomuceno, L. B., Bosi, M. L. M., Dimenstein, M., \& Pontes, R. J. S. (2021). Práticas de psicólogos na estratégia Saúde da Família: Poder simbólico e autonomia profissional. Psicologia: Ciência e Profissão, 41, 1-15. https://doi.org/10.1590/1982-3703003189629

How to cite: Nepomuceno, L. B., Bosi, M. L. M., Dimenstein, M., \& Pontes, R. J. S. (2021). Practices of psychologists in the Family Health strategy: Symbolic power and professional autonomy. Psicologia: Ciência e Profissão, 41, 1-15. https://doi.org/10.1590/1982-3703003189629

Cómo citar: Nepomuceno, L. B., Bosi, M. L. M., Dimenstein, M., \& Pontes, R. J. S. (2021). Practicas de psicólogos en la estrategia Salud de la Família: Poder simbólico y autonomía profesional. Psicologia: Ciência e Profissão, 41, 1-15. https://doi.org/10.1590/1982-3703003189629 